This item was submitted to Loughborough's Research Repository by the author.

Items in Figshare are protected by copyright, with all rights reserved, unless otherwise indicated.

\title{
Householders as designers? Generating future energy services with United Kingdom home occupiers
}

PLEASE CITE THE PUBLISHED VERSION

https://doi.org/10.1016/j.erss.2020.101615

PUBLISHER

Elsevier

VERSION

AM (Accepted Manuscript)

\section{PUBLISHER STATEMENT}

This paper was accepted for publication in the journal Energy Research and Social Science and the definitive published version is available at https://doi.org/10.1016/j.erss.2020.101615.

LICENCE

CC BY-NC-ND 4.0

\section{REPOSITORY RECORD}

Cockbill, Stuart, Val Mitchell, and Andrew May. 2020. "Householders as Designers? Generating Future Energy Services with United Kingdom Home Occupiers”. Loughborough University.

https://hdl.handle.net/2134/12357413.v1. 


\section{Householders as designers? Generating future energy services with United Kingdom home occupiers}

The increasing adoption of smart meters and smart home technologies in domestic dwellings affords new opportunities to collect data about householders' everyday lives, including their energy use. Current services designed to support householders in reducing their energy use predominantly push 'feedback' at householders with limited effect. New services are needed that better engage householders with their energy data and energy saving options in more meaningful ways, and /or facilitate broader energy saving behaviours. After householders had spent a year being immersed in their energy data, this study used a co-design approach with householders, researchers, designers and building energy technologists to generate a set of future energy-related services that would benefit householders. The results present 11 codesigned concepts for future services that support householders in making structural and behavioural changes around energy use, alongside concepts that use energy data to impact positively on future lifestyles. Opportunities, challenges and the implications for the design of future energy services are then discussed. The article closes with reflections on the role of the collaborative design approach used to generate these visions of the future.

Keywords: Co-design; Service Design; Energy; Smart Homes; Smart Data; Energy Services

\section{Highlights}

- Householders were immersed in their world of energy data for one year.

- Eleven service concepts developed were generated using a co-design approach.

- Services comprised: 'information tools', 'control tools', and 'game changers'.

- Traditional explicit energy feedback did not figure highly in these services.

- Key challenges were providing meaning, building trust and ensuring data privacy.

\subsection{Introduction}

In the UK, $29 \%$ of energy use is connected with domestic residential housing stock [1] and some 26 million dwellings require energy-saving retrofitting to reduce energy demand and loss. To meet the UK's drive to reduce greenhouse gas emissions by $80 \%$ of the 1990 levels by 2050 [2], much work is needed to encourage householders to make changes to their consumption behaviours and the 
energy efficiency of their homes and appliances.

A combination of government policy and technological change has opened up access to household energy usage data and opportunities for energy saving and other value-adding services for consumers. For example, the Smart Meter rollout in the UK [3] has enabled access to a household's real time energy use data, and the potential for detailed and up-to-date energy consumption feedback. Smart Meter data can also facilitate energy supply/demand management and provide feedback on variable energy pricing to capitalize on the opportunities provided by renewable energy supply. In addition, disaggregation algorithms can provide (within limits) a finer level of data at an appliance [4] or activity level [5] without the need for additional sensors within appliances or smart plugs. There has a steady year-on-year increase in the adoption of technologies for energy management and 'smart homes' more broadly [6] and continued efforts towards interoperability (e.g. [7]). This further opens up opportunities for a wide range of products and services that are targeted at the householder and are either derived from, or make use of, home energy consumption data.

Since the 1970's, 'energy feedback', (typically via an In-Home Display) has been shown to have some potential for measurable effects on household behaviours and attitudes towards energy consumption [8]. However, more recent research has suggested that there is little robust evidence of the efficacy of feedback with a comprehensive review of existing qualitative and quantitative evidence concluding that innovative feedback mechanisms that engage users with their energy consumption in more meaningful ways is needed [9]. Hargreaves [10], building on Buchanen's [9] findings, as part of a critical review of energy feedback approaches, calls for research that extends the debate beyond conventional approaches to energy feedback by focusing on: (1) practice-based approaches, (2) encouraging increased inventiveness in terms of policy, and (3) exploring experimental and speculative approaches to 'reframe the energy problem'. Strengers, Pink and Nicholl [11] similarly call for more inventiveness when exploring energy futures and the need to go beyond the limited 'socio-technical visions' at the heart of current energy policy initiatives. The 
need for more imaginative, and human-centred, approaches to household energy study is also promoted by Sovacool [12], and Stern [13] specifically calls for a trans-disciplinary approach in order to understand (and influence) individual and household interactions with energy systems. Renström [14] has developed the human perspective further by: (1) identifying how householders actually play many roles within energy related services, and (2) highlighting that potential energyrelated services for householders go beyond energy feedback.

This paper responds to the calls from [12] and [13] and builds on the human-centred perspective taken by [14] utilising a 'bottom up' co-design approach [15] to collaboratively develop future energy services by engaging households with their energy consumption. It reports the culmination of a process - stretching over a year - of joint exploration of their energy data and 'provocation' in relation to the various energy-saving measures that were available to them. By exposing households to their 'energy data world' over an extended period, it was surmised that householders would be able to generate a set of potential energy-related services that had relevance to them, and would also be able to critique them in order to identify particular challenges to their future development.

This study is based on the notion of co-design, a term commonly used to describe the involvement of "people other than those traditionally trained in design within design processes" [15], of which there are many stated benefits. Co-design is designing with - not designing for and views people as "experts of their own experiences" [16]. It typically involves designers and end users but can also include a wider range of multi-disciplinary collaborators. This study also involved building energy technologists (hereon referred to as 'technologists' for brevity) in the process - following the calls for cross-disciplinary collaboration [13]. Particularly in the more exploratory 'front end' of design processes, co-design is stated as having the potential to help to define "what should or should not be designed" [15] and is increasingly used in the design of services [17]. 
Although many human centred approaches (including co-design) have investigated and developed energy feedback with householders, only limited work has been done that actively codesigns future energy services with potential future end users (and wider stakeholders). Notable exceptions are Dove et al. $[18,19]$ who used 'interactive data visualisations' (i.e. graphical representations of energy consumption data information) as a prompt for creativity within service design workshops with customers of an energy supplier. More recently, De Wilde and Spaargaren [20] took a service design approach to gain feedback on three customer journey designs for low carbon retrofit services, using ethnographic fieldwork and interviews with stakeholders who would supply the service. The findings highlight how 'trust' is an essential and common ingredient for future services that are providing advice to householders, whilst also suggesting that more work is needed to better understand householders' motives for different types of service design.

Renström [14] undertook group sessions to generate visions for the future of smart energy systems. She investigated how householders viewed themselves in terms of their roles in future energy services, and also identified three categories of future energy services/systems ('information tools', 'control tools', and 'game changers'). This categorisation is adopted and extended in this article in relation to household energy demand reduction and also using energy data to provide broader insights into households and their activities in order to design value-adding services.

The aims of this paper are to identify future energy-related service concepts that are meaningful to householders. This includes highlighting what the services could offer to householders, what developmental challenges were foreseen, and what the key issues might be that need to be tackled for their future design and delivery.

\subsection{Method}

\subsection{Field Trial Overview}

This study describes the culmination of a 20-month longitudinal field trial and co-design process concerned with investigating the impact of smart meter and smart home technologies and the data 
they produce on the household's behaviours and renovation decisions (for more detail on the field trial and sampling criteria see [21] and [22]). The field trial installed smart meter and smart home technologies (e.g. gas and electric smart meters with in-home displays, room temperature monitors, occupancy sensors, and others) in 20 households from Loughborough, Leicestershire, UK, and collected householder energy data over a period of 12 months. The other group of 10 householders that formed the overall cohort of 20 were part of a more naturalistic study of energy behaviours, without any intervention, and lie outside the scope of this study. Contrasting Dove et al's [18, 19] work, the study reported in this article longitudinally immersed households into the world of their own smart meter and smart home data.

The field trial period ended with a study that co-designed future energy-related 'information-intensive' [23] service propositions to support householder's energy saving behaviours and decisions with the 10 participating households, technologists and human centred designers. This article is based on this final generative study.

Longitudinal Field Trial \& Wider Co-Design Process



Figure 1 Key stages and activities in the study (situated within the broader field trial)

The study comprised three distinct stages (Figure 1). Emphasis was placed on collecting data in a 
collaborative, interactive, and visually engaging manner, using a range of different materials and techniques. The perspective taken was congruent with that of co-design approaches i.e. that the householders were treated as "experts of their own experiences" [16] and that co-design approaches can help to "define what should or should not be designed" [15].

\subsection{Procedure \& Materials}

Stage 01 (see Figure 1) comprised a home research visit to ten households in Loughborough, Leicestershire, UK. The aim of Stage 01 was to investigate the potential role and usefulness of personalised smart meter and smart home data with the householders that had lived for a year with smart meter and smart home technologies using generative activities and prompted discussion. It was anticipated that without artefacts to 'talk about' the householders would find it difficult to comprehend and discuss the 'invisible' nature of energy data [24] and the 'intangible' nature of 'services' [25] during the study. Interactive and collaborative activities were introduced to support householders in making meaning around their energy data [22]. Visual prompts were used on the basis that: (1) they are commonly used in co-design to generate ideas [26], (2) they can provoke 'what if' scenarios [27], and (3) they can prompt comprehensive discussions and provide a common language for participants and researchers [28].

Each household participated in a 'forced association' [29] idea generation activity using a set of visual prompt cards (Figure 2, $3 \&$ 5). The cards included: (1) ten A6-sized 'data types' cards that represented different types of 'energy data' being collected from their home (e.g. whole house gas consumption, motion, internal room temperatures - Figure 2). The householders were asked to select individual cards or combinations of cards and to discuss the extent to which they felt they might find the data (or combinations of data) useful. Focus was placed on a broad scope of 'usefulness' (e.g. by exploring behavioural changes, or by improving home safety and security). A set of three 'lenses' prompt cards (Figure 3) was used to broaden the discussion with the householders, who were asked to consider the potential usefulness of the energy data from their 
own perspectives, alongside the perspectives of their household, and to think more broadly about the ways in which the data might be useful for their broader community, and why.
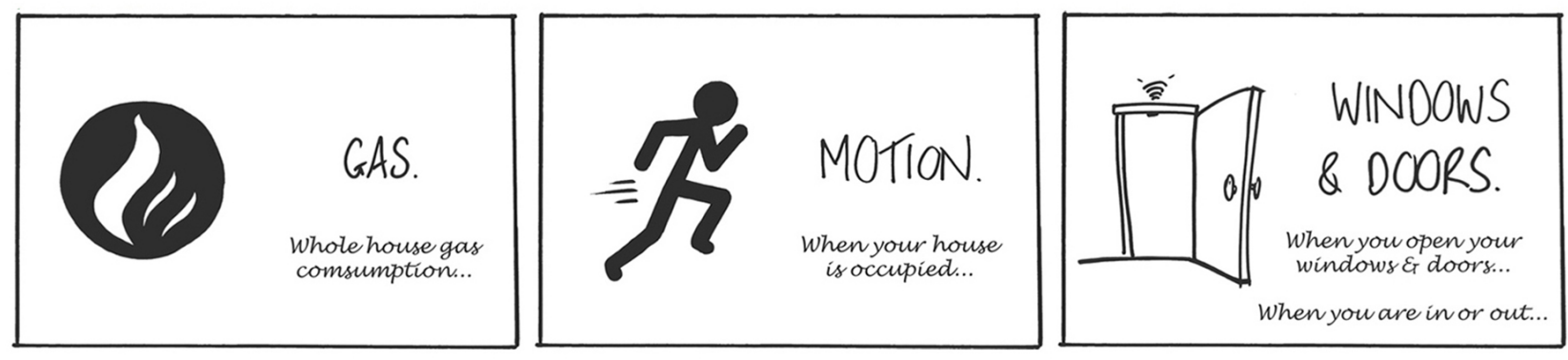

Figure 2 - Examples of the 'energy data'
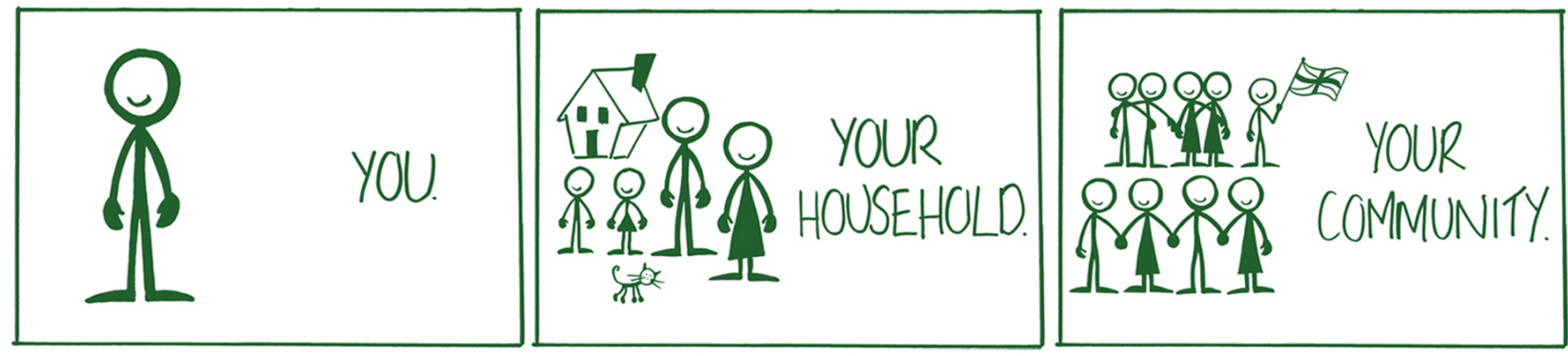

Figure 3 - Examples of the 'lenses' prompt cards

In addition, seven A6-sized cards were used to prompt the householders to make comment on which delivery channels they believed were most suitable for the different types of data. Two A5sized cards were used to help the householders better understand the link between their personalised energy data i.e. 'the things we know coming from your home', and the delivery channels i.e. 'the ways you can find things out'. These are shown in Figure 4. 

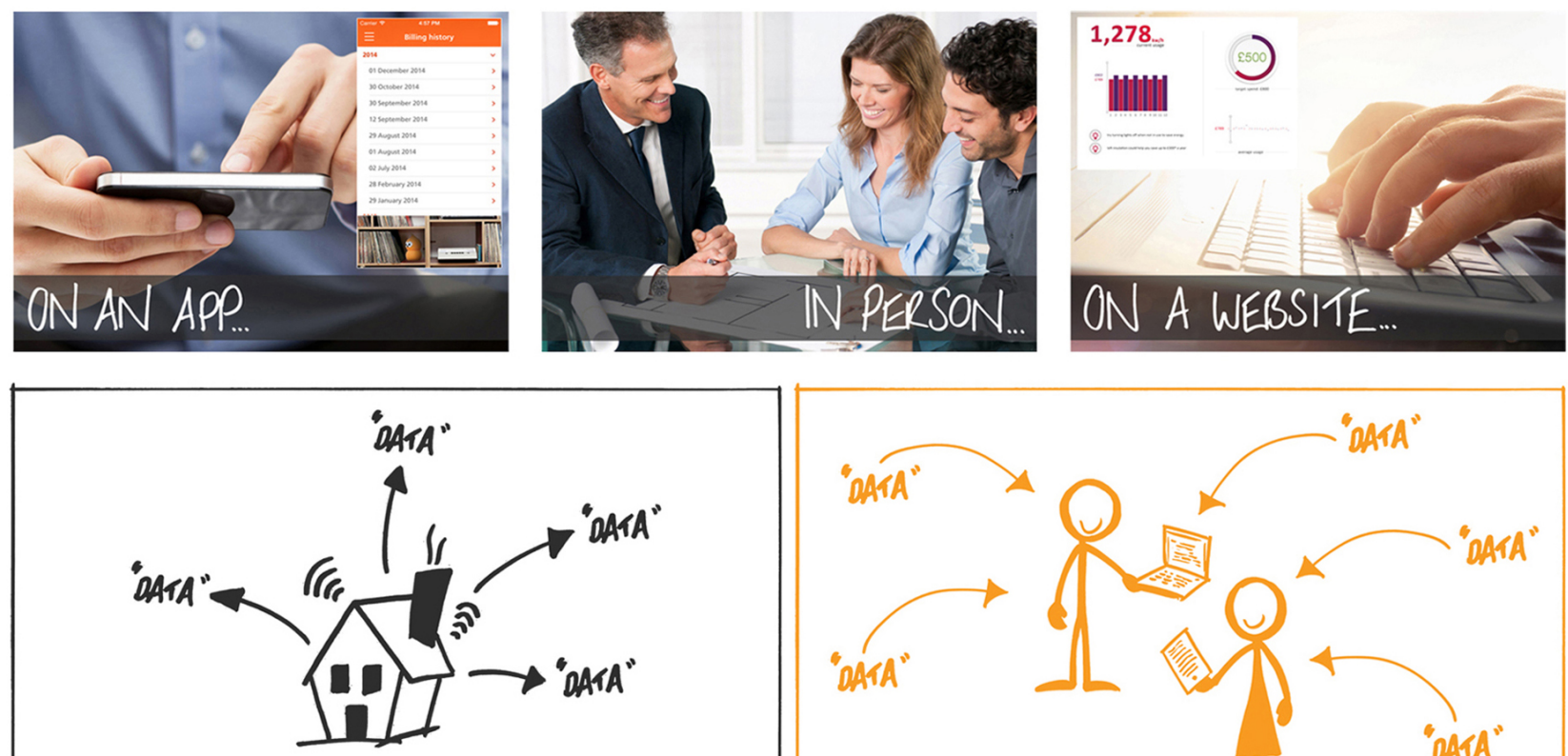

THINGS WE KNOW... COMING FROM YOUR SMART HOME...



Figure 4 - Examples of the 'delivery channels' and 'information' prompt cards

A verbal procedure protocol was used for Stage 01 which included a series of questions, prompts and a crib sheet for the 'data type' cards. The activity closed with an invitation to a future co-design workshop to discuss the outcomes from the study (and the overall field trial).
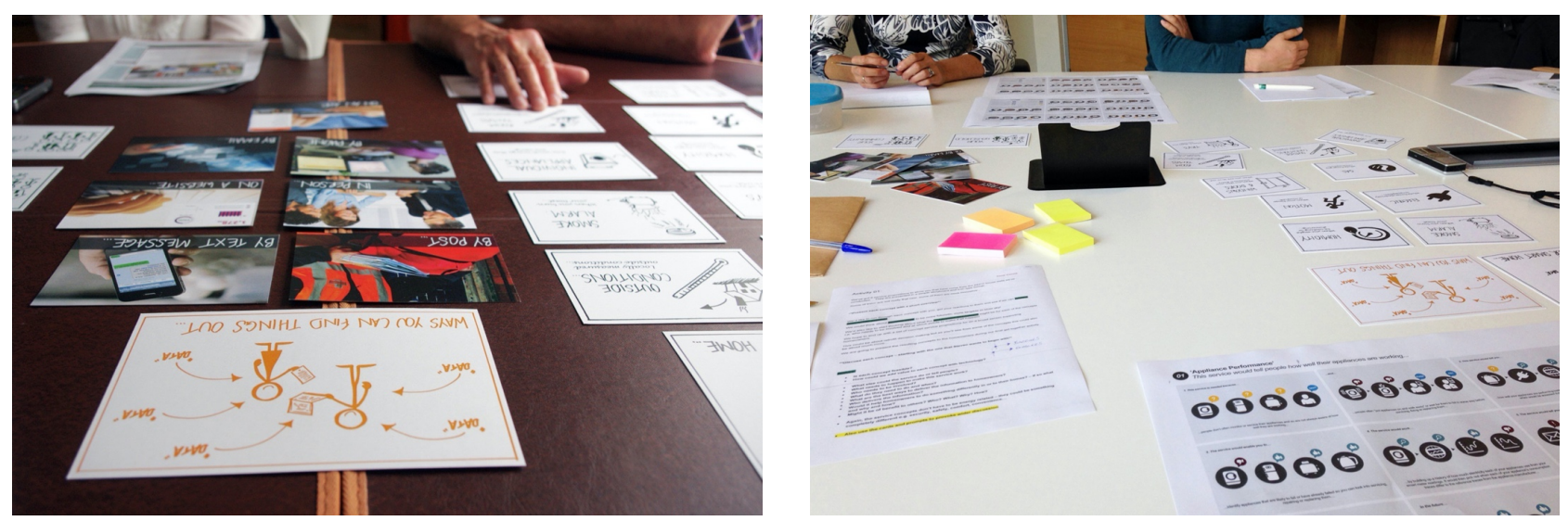

Figure 5 - Householders discussing energy data and delivery methods \& Figure 6 - Developing the service propositions with technologists and human centred designers

Stage 02 comprised a round table discussion (Figure 6) involving technologists and human centred designers. The aim was to gain insights to inform the development of the eight initial future service 
propositions (i.e. the results from Stage 01) using the insights generated. Four technologists with experience in end-use energy demand in domestic buildings, detailed energy monitoring studies, and ICT for energy efficiency, and two human centred design researchers participated with the two researchers facilitating the discussion. Although the four technologists had been involved, to varying degrees, in the running/supporting of the project, and were generally positive about the potential of technology for energy management, they had no vested interests or stated biases in relation to any of the services that were generated.

The round table discussion took the form of an evaluation workshop (i.e. a common method for evaluating outcomes from the design process [30]). The workshop was designed to be interactive and visually engaging and began with a brief overview of the initial service propositions and the process that led to their generation. The participants, guided by the facilitators, discussed the technical feasibility of the concept services. Topics included: (1) how the service could be enabled, what would have to happen, and who would need to be involved, (2) what might inhibit the service, and (3) how the service could be evolved in terms of scope and depth. Further discussion comprised ideas for any services that hadn't been covered. Ten minutes discussion time was allocated for each individual service. 


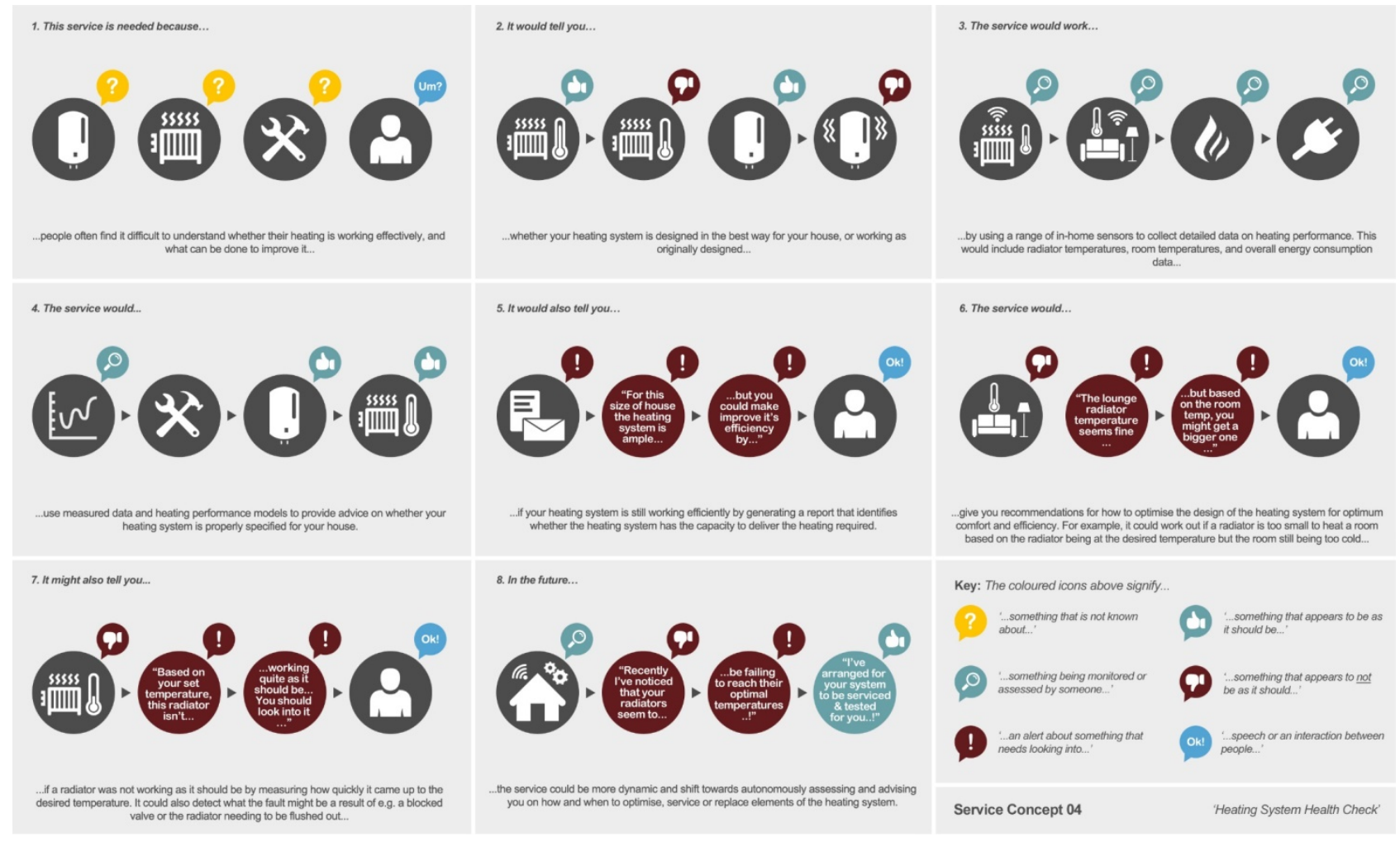

Figure 7 - Example of the 'Heating System Health Check' Service Proposition Storyboard

The services were portrayed in storyboard format on A3 paper (Figure 7): a common format adopted to convey the key aspects of service concepts and to prompt feedback on potential problem areas and areas of opportunity from designers and potential service customers [31]. An info-graphic style with simple one-line 'captions' was adopted to deliver the information in a bite size,

understandable and approachable format (in line with [32]). A verbal protocol document included a series of questions, prompts, and a guiding crib sheet that included a short description of each service concept. Key insights relating to each service proposition were extracted on a service-by service basis including comments on technological feasibility, what types of data and monitoring would be required to provide a good quality service (e.g. whether the data would be trusted by householders), and whether the participants believed that householders would find the service and their features useful.

Stage 03 comprised a co-design workshop at Loughborough School of Design and Creative Arts. The aim was to capture additional insights and householder feedback on the 11 developed future service propositions from Stage 02 . Ten original households from Stage 01 were invited to 
participate, however only four households were able to attend (i.e. six individual householders in total). The workshop comprised two round table discussions focused on exploring whether the services presented were meaningful, useful and desirable, whether they could be further improved in terms of depth, breadth and innovativeness, and what key challenges to their development existed. Bringing the original householders back to evaluate the services was expected to enable well considered reactions and effective feedback based on their longer-term sensitisation to 'smart energy data' and the study context [33].

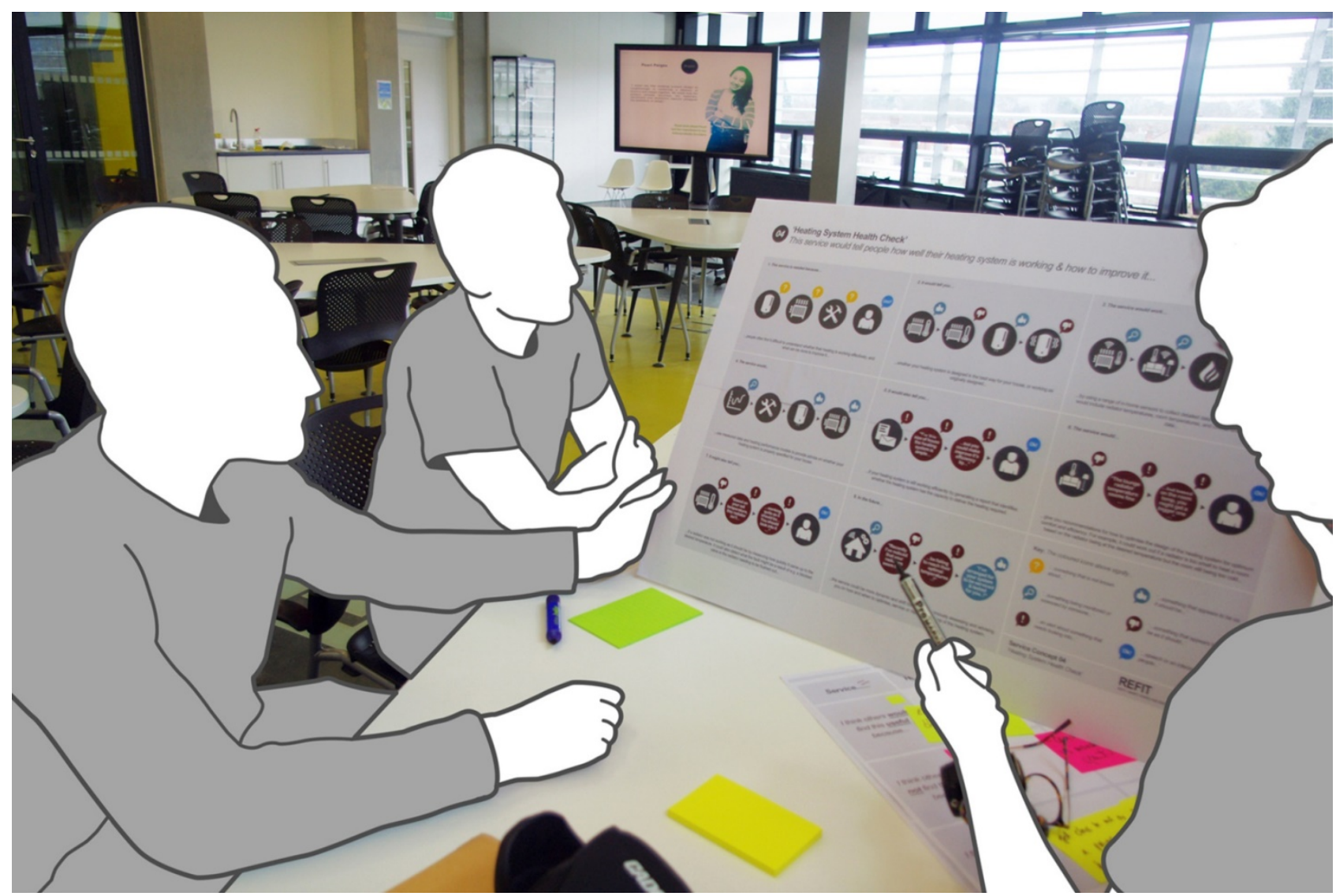

Figure 8 - Households discussing the future service propositions with the facilitators

The 11 energy-related service propositions were again portrayed in a simple info-graphic storyboard format and mounted on A1 card (Figure 8). Additionally, two A2-sized 'feedback frameworks' were designed for the householders to add written comments for each service concept and to prompt them to consider the future service propositions from three different perspectives: (1) how useful they perceived each service to be for themselves, (2) how useful they perceived each 
service to be for their collective household, and (3) how useful they perceived each service to be for others. The cues included on each feedback framework were designed to prompt the householders to 'fill in the blanks', based on [34]. For example, 'my household and I would find this useful because...' and 'my household and I would not find this useful because...' were included to spur positive and negative comments on the service propositions. A verbal protocol document including a series of questions, prompts, and a guiding crib sheet was used by the facilitators where required.

\subsection{Data Analysis}

The data from Stage 01 included an audio recording of each household's home research visit. Using the audio recording, detailed notes were made for each mention of an emotional and/or behavioural need, challenge or opportunity. For example, one household (with solar panels) said: "if I have to put the dishwasher on, and it isn't sunny, well that's a failure!". Service concepts were generated by the human centred design team to address the need, challenges, and opportunities that emerged. These concepts were then aggregated and synthesised, and abstracted if necessary, in order to create a single parsimonious set of service propositions that were derived from the householder data. A narrative was created for each service comprising: (1) rationale for why the service was needed, (2) what the service would tell the householder, (3) what the service would enable the householder to do, (4) how the service would work, (5) how the service would inform the householder, (6) examples of what the service might monitor, and (7) what the service might look like in the future. Each service was presented in a visual info-graphic storyboard, with simple one-line 'captions' (see Figure 7). The concepts were based on the householders perceived usefulness of their smart meter and smart home data, and were designed to support individual householders' and collective households' energy-related retrofit decisions, and more broadly, to support issues such as safety and security in the home and wider community, and how 'energy' might be used to help build community spirit. 
The data from Stage 02 included an audio recording and a collated set of notes from several participants. Based on the technical and systems-thinking expertise of the technologists and the generative nature of Stage 02, the eight initial future service propositions were developed during the collaborative session as follows: an initial service concept about heating system design and control was developed into two conceptually distinct service concepts: (1) one that focussed on the technical design of householder's current heating systems and (2) one that focussed on setting up heating systems and their controls. Two additional service concepts were also introduced. 'Community-Based Services' focused on sharing energy information within a community to support it's members through sharing surplus energy, and to help householders to collectively shift their energy supply and demand. 'Energy Education' was a dedicated scheme to increase awareness of the wider energy saving issue via education in schools. Eleven future service propositions resulted (see Tables 1-11) and were presented as info graphic-based storyboards (Figure 7).

The data captured from Stage 03 included audio recordings and research notes. Key discussion points were extracted on a service-by-service basis. These included: (1) the perceived advantages and usefulness of the services to the householders and others, (2) the perceived disadvantages of the services, (3) views on the feasibility of the services in terms of technology, (4) what the householders thought might inhibit the service in terms of quality e.g. trust or access to data, and (5) what might make the service more useful to the householders and others. Insights from the householders were used to identify implications for the design of future energy services, discussed in section 5.0.

\subsection{Results \& Discussion}

The collaborative co-design process generated opportunities for 11 future energy services that could use 'smart data' to support reductions in energy demand and energy loss in households in diverse ways. Section 4.1 (Tables 1 to 11) details the 11 services and sets out the perceived advantages of each service from the householders' perspectives captured in Stage 03. Key requirements for the 
further development of each service are also included based on householder feedback.

Section 4.2 then sets out in more detail how future energy services might offer 'value' to householders, by discussing the service opportunities in relation to Renström's [14] three classifications of 'smart energy tools': (1) information tools, (2) control tools, and (3) game changers. Section 4.3 critically reflects on the services generated and sets out implications for the design of future energy services including how they may account for the roles householders foresee themselves playing in future energy services and systems [14].

\subsection{The 11 Service Opportunities Generated}

01 - Green Deal 'Plus' - Home Energy Audit:

This service would build on the advice that was given through the now discontinued UK government's Green Deal [35], by incorporating an energy audit that includes a detailed householder-consultation process - to provide more contextually relevant advice to the householder.

\section{Summarised Householder Feedback}

Key Requirements for Further Development

- One-off energy audit is good to help people think about their home and energy use.

- Helps to give people a clear idea of how much energy they use and points out area's that haven't been thought about.

- Offers an 'independent eye' and uses 'real data'.

- Some might find it interesting, informative and useful (e.g. those who are selling their homes).
- Ensure that participating householders do not feel they are having their privacy invaded.

- Ensure recommendations are appropriate, relevant and bespoke to the household.

- Ensure comparisons to other similar households are as contextually accurate as possible.

- Identify mechanisms to attract the right target audience i.e. the 'disengaged' who pay their bills and forget about it but could benefit the most.

- Explore ways to engage householders longitudinally through e.g. follow up audits, remote audits, increasing levels of detail.

- Provide 'added value' for those who are already 'engaged' but want to do more. For example, Cosar-Jorda et al. [36] have demonstrated how personalised data could be used to inform householder decision making beyond retrofit. 
Table 1 - Summarised Householder Insights on Service Concept 01

\section{2 - Understanding Appliance Consumption:}

This service would comprise detailed monitoring of consumption by appliances and comparing this to similar households, to highlight where consumption is 'normal', and where easy cost savings should be possible.

\section{Summarised Householder Feedback}

Perceived Advantages of Service

- Based on 'real data'.

- Would support decisions between using gas or electricity for heating.
Key Requirements for Further Development

- Provide householders with options to compare with other households or appliances for those who are interested.

- Ensure comparisons to other households and appliances are contextually accurate.

- Provide 'levels of granularity' to enable householders to 'dig into detail' if they want to.

- Give householders options for alerts if energy usage increases by a lot and they do not want to monitor their appliances themselves continually.

- Integrate appliance efficiency with other features that people use to choose appliances to support replacement decisions.

Table 2 - Summarised Householder Insights on Service Concept 02

03 - Appliance Performance Monitoring:

This service would use disaggregated electricity consumption to identify when individual appliances are failing or becoming less efficient.

Summarised Householder Feedback 
- Could look at boiler efficiency levels using room temperature and gas data.

- Could monitor fumes from appliances (e.g. carbon monoxide) for safety reasons.
- Provide historical comparisons to enable householders to easily check if appliances are performing well.

- Provide early warning signs to alerts householders to potential appliance degradation.

- Build in facilities to integrate with other 'metrics' e.g. prompt householders to visually inspect appliances such as assessing how white 'whites' come out of a washing machine to increase the accuracy of diagnosis.

- Build trust with householders that might be sceptical about trusting their own appliances or manufacturers to tell them they are broken or faulty.

Table 3 - Summarised Householder Insights on Service Concept 03

\section{4 - Heating System 'Health Check':}

Using temperature and energy sensors to analyse heating performance and recommend design changes to heating systems.

\section{Summarised Householder Feedback}

\section{Perceived Advantages of Service}

Key Requirements for Further Development

- Ensure that any technical advice given is delivered in understandable terms.

- Identify mechanisms to engage those that might not care or are not interested but might benefit the most.

- Consider how householders might be encouraged to invest in the costly smart home equipment required - promote the 'added value'

- Consider how the service might be scalable to alternate heating systems e.g. heat pumps, oil fired boilers.

Table 4 - Summarised Householder Insights on Service Concept 04

\section{5 - Setting Up Your Heating:}

This service would use sensors such as room temperature, occupancy, and activity levels, to identify

how well heating system controls (or programming) are set up and how they can be optimised to 
balance comfort and cost.

\section{Summarised Householder Feedback}

Perceived Advantages of Service

- Could help people work out how to achieve comfort for lesser cost.

- Would provide improved flexibility over heating control.

- Would help to improve comfort and save money.
Key Requirements for Further Development

- Consider how householders might be encouraged to invest in the costly smart home equipment required - promote the 'added value'

- Ensure that monitoring equipment from different manufacturers is compatible and can be integrated into smart home systems.

- Find new ways to generate interest in households that just want their heating on or off through reframing how 'heat' is paid for, delivered and controlled. Similar services (e.g. 'Heat as a Service') have been conceptualised and trialled by the Energy Systems Catapult [37] to generate household engagement in new ways.

Table 5 - Summarised Householder Insights on Service Concept 05

\section{6 - Utility Cost Comparison:}

This service would use detailed monitoring of energy usage and direct comparison of actual costs of various energy suppliers to provide recommendations or automatic and dynamic switching of energy supplier. Similar services that help householders reduce peak-hours energy consumption have also been conceptualised by Dove et al. $[18,19]$ in conjunction with an energy supplier.

\section{Summarised Householder Feedback}


- Helps people to conserve energy.

- Provides ability to benchmark tariffs against others nearby e.g. neighbours next door.
- Enable householders to have the level of control over automated switching that they want.

- Ensure the service is simple and easy to use, especially for older generations.

- Find ways to encourage more of the population to switch their energy supplier more frequently to enable greater number of switching options, tariffs and new models around energy supply.

- Ensure that energy suppliers 'buy in' to the scheme and are transparent when providing data to enable householders to make the best decisions.

Table 6 - Summarised Householder Insights on Service Concept 06

07 - Energy Supply \& Demand Management:

This service would help householders manage their energy supply and demand by taking into account the times of day, or days of the week when energy is cheap or free (e.g. through microgeneration) and helping to schedule appliance use accordingly.

\section{Summarised Householder Feedback}

\section{Perceived Advantages of Service}

Key Requirements for Further Development

- Would make it easier for people to decide when to use certain appliances.

- $\quad$ The idea of sharing surplus energy is positive, although those with renewables already do this to an extent by sending it back to the grid.

- Would offer more localised benefits rather than sending energy back to the 'big 6'.

- Others could benefit from excess energy.

- $\quad$ Those in social housing who are unaware could benefit based on learning about themselves and others around them.
- Provide added value for householders who are already interested and engaged with better managing their resources.

- Find ways to encourage people away from 'conveniences' by supporting them in adapting their lifestyles around renewables and acting more energy efficiently.

- $\quad$ Find financial means to rollout localised infrastructure that can enable people of all groups to participate.

Table 7 - Summarised Householder Insights on Service Concept 07

08 - Safety \& Security Alerting:

This service would use various sensors in and around the home to monitor and alert when safety and/or security is being breached. 


\section{Summarised Householder Feedback}

- Carbon monoxide detection would be really useful because it can't be smelt.

- Would be useful to detect unlocked or open doors and windows.

- Would be useful for monitoring elderly relatives.
- Deliver the right messages at the right time e.g. avoid causing distress by delivering bad news to someone on holiday.

- Build in mechanisms to alert appropriate 'next of kin' (e.g. family, friends, neighbours) that can deal with issues on householders' behalf, and in extreme cases the emergency services.

- Provide mechanisms to ensure people can trust others to help them out in their time of need.

- Provide means for older generations to learn or cope with the technology that could ultimately improve their well-being and safety.

- Alleviate the 'big brother' feeling (e.g. the feeling of being constantly watched by others).

Table 8 - Summarised Householder Insights on Service Concept 08

09 - Community-Based Services:

This service would enable sharing of information on energy consumption within a local community to help members of the community (e.g. vulnerable isolated individuals), to support learning from collective experience, and to promote bulk energy buying or generation in a community.

\section{Summarised Householder Feedback}

Key Requirements for Further Development

- Giving surplus energy to those who need it is a good thing to do.

- Donating energy would improve the sense of 'community'.

- It would be useful if everyone took part as sharing ideas would promote community spirit.

- Could be implemented in community housing schemes to support those in danger of fuel poverty through sharing surplus energy.
- Find financial means to rollout localised infrastructure that can enable people of all groups to participate.

- Alleviate the 'big brother' feeling (e.g. the feeling of being constantly watched by others), especially for vulnerable groups.

- Ensure data protection is secure and robust especially for those who are wary of being 'hacked' and having their data ending up in the wrong hands.

- Provide safeguards that prevent people abusing the scheme by taking out and not putting back in. 
Table 9 - Summarised Householder Insights on Service Concept 09

10 - Targeted Training \& Awareness Raising:

This service would capitalise on specific life stage related windows of opportunity to bring about changes in energy related behaviour and attitudes by providing targeted energy efficiency messages at groups who may be more receptive, e.g. targeting older households who may have time and motivation to consider energy usage or couples expecting a child.

\section{Summarised Householder Feedback}

- The service would help those who are not technology or energy 'savvy'.

- It would promote the benefits of saving energy to others - awakens needs and recognition that savings can be made.

- It can target specific 'windows of opportunity'.

- Makes people aware of the benefits of saving energy.
- Find ways to engage groups that could be more receptive to information and advice, given that they may also have limited time, interest and other prioritise.

Table 10 - Summarised Householder Insights on Service Concept 10

\section{1 - Energy Education:}

This service would bring about changes in energy related behaviour and attitudes by integrating targeted energy efficiency messages into the school curriculum to instil early messages in school children.

\section{Summarised Householder Feedback}


- Competitions make it (i.e. saving energy) 'cool'.

- Companies could 'buddy up' with local kids and help them to learn about energy based on their experiences.

- Helps people to make new connections.

- Gives a sense that people will be helping future generations.

- Helps to educate others to care for the environment.
- Build solid cases for attracting funding.

- Find ways to attract and onboard 'the sceptics' (e.g. adults moan about schemes like this such as healthy school dinners).

- Incorporate different ways of associating energy use with everyday life, not just costs.

- Consider that not all households have children and find ways to engage those that don't.

Table 11 - Summarised Householder Insights on Service Concept 11

\subsection{How the Services Generated Offer 'Value' to Householders}

\subsubsection{Services that Provide Energy 'Information'}

Ten of the 11 identified service opportunities primarily aligned with Renström's [14] 'information tools' category. Services 01 through to 07 were based on collecting measured smart energy and smart data and using this to provide general or context-specific information, suggestions, reminders or prompts to householders about their energy use, their behaviours, their potential courses of action in relation to retrofit options, their appliance usage, and their energy supplier and tariff. For example, the 'Home Energy Audit 2.0' would use actual measured energy consumption figures to deliver accurate predictions of estimated energy and cost savings from changed behaviours and retrofit. Another example included 'Appliance Performance Monitoring', which would provide straightforward information such as how much energy an appliance uses in understandable terms, comparisons of appliance consumption in relation to other contextually similar households, and suggestions for how making cost savings e.g. information about purchase options for new appliances. 'Targeted Training \& Awareness Raising' and 'Energy Education' were also based around smart energy data and smart home data, but using it in a slightly different manner to push messages to those who might be more receptive to making changes in their everyday lives or even compromises [14] e.g. new house buyers could be prompted to opt for a more efficient new build house over prioritising an older less-efficient house with 'visual character'. Finally, 'Safety \& 
Security Alerting' focused on using the same 'data' but for a different purpose: i.e. that of identifying and then providing information, alerts and reminders to householders about potential safety and security breaches in their home.

\subsubsection{Future Services that Enable 'Control' of Energy}

Six of the 11 service opportunities ( 03 through to 08 ) generated also aligned to the category of services that would use smart energy and smart home data to enable householders to exercise 'control' over their energy use and any artefacts associated with this in their homes [14], on top of being provided with 'information'. These services all displayed potential for new ways of enabling control over energy use, going beyond the level of information provision only. 'Energy Supply \& Demand Management' was designed to extend the control of the householder over their appliances. This service would remove the burden around decisions of when to use particular appliances, would automate appliance usage based on time of day or when energy is cheaper, and could even incorporate machine learning/AI to manage and control appliances to balance energy supply with household needs (e.g. automating the washing machine to get the washing done on time for convenience but also when energy is cheaper or in surplus).

'Utility Cost Comparison' was designed to automatically and dynamically shift energy provider and tariff on behalf of the householder if they prefer, removing the burden of keying in figures to comparisons sites to get the 'best deal' through automating the information input and searching process using smart data. 'Levels of control' were also identified in 'Appliance Performance Monitoring' whereby manual control of appliances could be enabled through an app (e.g. to turn hair straighteners off if a householder has forgotten). Automation was also a feature of this service whereby appliances could be automatically controlled on behalf of the householder should they become faulty, with machine learning/AI having the potential to learn about appliances over time, identify likely faults and to automatically condemn their usage should they become 'high risk'. 


\subsection{3 'Game Changing’ Future Energy Services}

Seven service opportunities have the potential to be 'game changers' i.e. those that help to change the preconditions for energy use. These service opportunities move beyond providing information and enabling control by introducing new ways of using, storing or producing energy [14]. 'Appliance Performance Monitoring' helps householders to identify failing appliances and alongside suggesting energy efficient replacements also offers householders 'alternate ways of doing'. For example, recommendations for new and even different appliances for particular household activities would be provided based on energy consumption, usage patterns and household context. The service could even question householders over the need for particular appliances when the need for a replacement arises.

'Setting Up Your Heating' moves beyond information and control to offer rewards and incentives for using heating systems more efficiently. This service would help householders to find new ways to balance their household activities with their desired comfort levels with energy reduction in mind. For example, instead of drying clothes on the radiators at a cost to comfort and increased energy use from keeping the heating on, recommendations would be given of different ways clothes might be dried. Furthermore, this concept could help prompt changes in preconditions of energy use for families moving into new build homes by building it into the 'new build package' as a 'standard feature or service' that promotes resource efficiency and alternate ways of doing. Service 06 could extend to promoting and supporting mass shifting of energy suppliers by sourcing and offering better deals for groups of householders e.g. for entire communities to shift to a particular local supplier (e.g. small-scale local micro-generation suppliers). 'Energy Supply \& Demand Management' extends to prompt sharing of surplus energy offering more localised benefits e.g. by connecting those with renewables and storage capacity in a community and enabling them to dynamically share their supply in relation to their demand and context. 


\subsubsection{Services that 'Go Beyond' Energy}

The service opportunities generated in this study also provide the opportunity to expand on the three categories generated by Renström [15] and to respond to Hargreave's [10] calls for policymakers and service providers to become more inventive around future policy and service development. An additional category of opportunities for future energy services became apparent that suggests new roles for smart energy data and smart home data. 'Appliance Performance Monitoring' for example, has the potential to go further than identifying appliances that are degrading in energy efficiency and can incorporate new ways of increasing safety in the home by identifying faulty appliances e.g. the electricity 'signatures' of 'higher risk' appliances such as tumble dryers and automatically alerting householders and/or appliance manufacturers to faults.

'Safety and Security Alerting' uses energy and 'data' as an entry point for improving and ensuring safety and security in the home and within a community. The consumption of energy is inextricably linked to daily activity. This service identifies potential breaches of safety and security and uses networks to alerts 'next of kin' or neighbours who can deal with an issue if needed and in more serious cases can alert the relevant authorities to enable rapid response if needed. Similarly, 'Energy Community' uses smart energy and smart home data to enable people to check on their elderly parents or relatives (remotely) and provide improved 'care from a distance'. This service also supports building of community around and through energy with an emphasis on the safety and well-being of particularly vulnerable individuals within a community. For example, reductions in energy use and internal temperatures during winter months shown by smart energy and smart home data of a particular dwelling could suggest that someone might not be putting their heating on for fear of cost, or whether something more serious has occurred and helped is urgently needed.

'Targeted Training \& Awareness Raising' and 'Energy Education’ push the boundaries even further using smart energy and smart home data as tools to provoke change through identifying and targeting messages to those most susceptible to change. Both services are designed to deliver key messages at critical moments to groups such as those planning on moving home, those planning on 
renovating, those who are newly retired with disposable income, and younger generations who are more concerned with environmental issues and more open to becoming 'change-makers'. In these services 'smart data' becomes the catalyst for discussion of the need for energy demand reduction enabling the issue to be put at the forefront in homebuying services, home renovation services and the curriculum.

\subsection{Design and Delivery Implications for Future Energy Services}

\subsubsection{Trust}

For future energy services that provide information to householders such as alerts, prompts, reminders or advice around replacing appliances alongside offering levels of control or automation, there is need to ensure that the information delivered is 'accurate' and 'trustworthy', that it is delivered by trustworthy suppliers, and that such suppliers can be trusted to operate on the behalf of the householder for their benefit. For example, services that monitor and inform of appliance degradation were viewed sceptically by the householders in this study for two key reasons: (1) that it was believed not possible to fully assess how well an appliance is functioning from electricity consumption alone (i.e. there are more metrics such as how white a washing machines can get white loads), and (2) that appliance manufacturers or suppliers could 'game' the results in their favour, especially around suggesting appliance replacements and automatically switching of energy tariffs or suppliers. Future energy service providers need to build trust with householders if they are to provide information to them to inform their decisions, and even more so in cases where they are offering control-based service features such as automated switching. Whilst automated switchingbased services will most likely appeal to the 'passive' and those who prioritise 'convenience' [14], they still must operate with the householder's best interests in mind. Similarly, De Wilde and Spaargaren [20] have also identified 'trust' as essential for future services that are providing low carbon retrofit advice to householders. 
At the community-based future service level, the householders in this study were favourable towards the idea of localised energy generation, control and sharing of surplus energy, and schemes that could facilitate a move away from the 'big 6' (i.e. the United Kingdom's largest energy suppliers, supplying gas and electricity). However, householders also expressed concerns around 'sharing' services through fears that some people might abuse these services by taking energy and not giving any back in return. Services facilitating community generation and sharing of energy should incorporate safeguards to prevent abuse and to enable trust building amongst community members participating in these schemes. These services might fare better in the first instance by targeting individuals that might be willing to compromise other needs in favour of prioritising reducing energy use but should explore how they might encourage others (i.e. those less willing to 'get involved' for the greater good in favour of prioritising conveniences for themselves) [14].

\subsubsection{Meaningful Information Provision}

Services designed around providing information to householders through prompts, reminders and alerts need to also ensure that the information they provide is made meaningful at the individual or household level. For example, in this study, contextual comparisons of energy use in relation to other 'similar' households (in the study sample) were viewed with interest yet apprehensively, with many householders disliking comparisons against other households where context was lacking. Contextual comparisons (if incorporated) should be contextually accurate as far as possible (e.g. house, household type, location) to enable householders to draw meaningful comparisons.

In terms of levels and quantities of information about energy in the home, future energy services should be mindful that more and more information doesn't necessarily encourage energy saving or renovations to reduce demand and loss. In this study, householders highlighted the need to engage the disengaged with the view that some of the services would not appeal to this group on the basis of a lack of interest in the topic or 'information overload'. Considering Renström's [14] roles for householders in future energy systems, future services should account for those at both ends of 
the spectrum in relation to both 'interest and awareness (of personal energy resource use) in everyday life' and 'type of everyday involvement' in resource use reduction. They might do this by: (1) remaining conceptually simple, (2) automating actions to manage resources and remove difficult decisions, and (3) increasing convenience for some groups of householders (i.e. the 'passive' and 'convenience seekers'), whilst also building in capacity to increase information detail, advice and automation level as and when required by other groups of householders (e.g. the 'active controllers and managers of personal energy resources'). Future services should dynamically cater for increasing levels of interest, expertise and engagement with energy, enabling their users to define the level of detail and information they require and empower them to 'drill down into the detail' if they wish.

A further consideration of services that provide information is also appropriate and timely delivery. Services that focused on home security need to be sympathetic to when householders require information and carefully consider the timeliness of information delivery. Householders in this study disliked the idea of being alerted about issues with their home whilst unable to act (e.g. when on holiday). Instead, these services could use smart energy and smart home data to identify breaches of security and the best course of action to take regarding alerts and action. For example, service could incorporate 'smart back up plans' for when issues occur (e.g. contacting a neighbour or relative that could deal with the issue on behalf of a householder).

\subsubsection{Security \& Privacy Around 'Data'}

Ensuring security and privacy of householders were also highlighted as key considerations for future services, especially those that monitor entire homes to identify safety and security breaches. The monitoring aspects of these services were viewed sceptically by some of the householders due to the 'Big Brother' syndrome; the feeling of being continually under surveillance. Further, smart energy data and smart home data that is used to identify whether someone has left the heating on when they are out or to identify vulnerable community members need assistance can also be open to 
misuse i.e. to determine whether or not a house is empty. Services that offer remote monitoring therefore need to build trust with householders and build in appropriate and trusted safeguards around data privacy. This will be especially essential in services that monitor vulnerable members of a community.

\subsection{Developing Service Propositions with 'Experts of their Own Experiences'}

A key element within this study was the ongoing exposure of the participants to their own personalised energy data and their first-hand experiences of living with smart meter and smart home technologies, as a means of informing the generation of future energy services. The process of generating the initial ideas for the services in Stage 01 based on the householder's experiences appeared successful; the benefits were in line with those stated in the co-design literature, especially those pertaining to co-design in service design settings (e.g. [16]). The themes and ideas for the service propositions and the information and advice they would deliver emerged from the householders, prompted by their longitudinal experiences and exposure to the topic area. Although the resultant services were not necessarily that novel, they were systemic in nature. This suggested that the co-design process employed was beneficial especially in relation to 'going beyond' energy feedback [10], but also made clear the important role of the designers in prompting the householders to consider the role of smart energy data from multiple perspectives.

The householders' longitudinal immersion and inclusion in the co-design process had several observed benefits. Reaction to many of the services presented in Stage 03 were positive with useful insights obtained on which services (and specific aspects of the services) the householders believed useful for themselves, their households and others (e.g. their communities). The householders were also able to comment on which services and/or aspects of them that they felt were not particularly useful or in one case technically feasible, with 'Appliance Performance Monitoring' not being feasible as it would have to account for 'subjective' metrics such as the degree of whiteness of clean clothes. The findings are in line with the stated benefits of co-design such as defining "what should or should not be designed" [15], and the benefits of 're-using users' 
at different points across the design process to obtain richer and more diverse feedback [33]. The series of personal energy data provocations used during the co-design process gave the researchers greater confidence that the householders feedback was valid given their level of immersion in the energy context over the previous year.

\subsection{Developing Future Service Propositions with 'Technologists'}

Building energy technologists co-developed the future service propositions in terms of technological and market feasibility, whilst human centred designers offered insights from a householder perspective. Improvements were made to some of the concepts based on the insights obtained. This included simplifying information delivered and dividing some of the concepts to reduce the scope of information so not as to overload householders. This increased the breadth and the total number of potential future service propositions. The benefits for the design team of working closely with the small team of technologists were in line with those stated in the literature such as: (1) determining concept feasibility with regard to technology, manufacturing, engineering or financial constraints, and (2) allowing for more advanced, critical assessments of prototypes for products, services, technologies, experiences and environments [38].

\subsection{Limitations \& Future Work}

There were several limitations with this research. Since it was a detailed, situated and longitudinal study from a qualitative perspective, a relatively small participant sample ( $\mathrm{N}=10$ households) was involved. This enabled intense and multi-method data collection but limited the diversity of the study sample. In addition, the same set of householders were used to co-design and develop the future service propositions. Although this meant the householders could give richer and more detailed feedback (following their continued immersion in the application context - in line with Visser and Visser [33]), there was also a danger that they could have fixated on the services that were based on their own individual ideas or that they thought were most useful to their own personal needs. The community focus of many of the service propositions suggests that this was not 
the case in this instance, but further validation with a broader set of householders would be beneficial.

The future service propositions were also based only on the experiences of those who engaged with the 'smart energy data' field trial. Despite capturing comments from the householders on their perceptions of the usefulness of the services to others in their wider communities, stating with confidence whether the energy-related service propositions are representative of services that might be useful and taken up by the general population is problematic. Without a comparison group, it is also not possible to state whether the same set of ideas would have emerged from a group of householders who had not been exposed to the smart energy data. Future work could seek to validate the services with a 'fresh' group of householders to better assess the extent to which they are more broadly generalisable.

The visual info-graphic storyboard format used to portray the future service concepts was also problematic for some of the householders to understand without support from the facilitators. Future work could employ more immersive approaches including (but not exclusive) to rehearsing digital services [39], or 'service staging': an approach that physically acts out scenarios in real world situations to show how services would be delivered [31]. Such immersive approaches might increase levels of understanding, but however are not without their own limitations, such as the time and resources required to run them. Future work could also incorporate customer journey mapping and service blueprinting to describe in more detail user journeys through the services and the key touch points encountered [40].

\subsection{Conclusions}

This article has presented and discussed the outcomes of a study designed to collaboratively ideate, develop and iterate concepts for future energy service propositions with householders. The findings show that there are opportunities for energy-related services to support householders in a variety of ways: incorporating actual measured energy usage data into home energy audits to improve and 
personalise the advice given; capitalising on windows of opportunity to engage householders with their energy use, targeting specific groups that might be open to change due to their life-stage; improving safety and security in the home; and incorporating energy into education and curricula. The perceived benefits and drawbacks of the services created were captured to inform key considerations for the development of future energy-related services. These included ensuring the trustworthiness of service providers, providing the right amount of scope, detail, depth and volume of information for specific individuals, the need for meaningful contextual comparisons, ensuring appropriate timeliness of information delivery and balancing automation with user control.

From a methodological perspective, the approach taken suggests that engaging co-design approaches are useful for helping householders to understand the intangibility of 'energy'. The findings highlighted that the householders involved in the study were well placed to contribute to the ideation of future service propositions based on their growing understanding of their own tailored and personalised energy information and its potential role and use to them. Development processes for future energy-related services should strive to actively design with householders (using similar tools and techniques applied in this study) providing wherever possible personalised data from the participant's homes, alongside incorporating insights from wider stakeholders (such as building energy technologists) to develop concepts feasible from a technological perspective.

\subsection{Acknowledgements}

This work was supported by the REFIT project ("Personalised Retrofit Decision Support Tools for UK Homes using Smart Home Technology,” $£ 1.5 m$, Grant Reference EP/K002457/1) which was funded by the Engineering and Physical Sciences Research Council (EPSRC). For more information see the following website: www.refitsmarthomes.org.

\subsection{Declaration of interest statement}

'Declarations of interest: none'. 


\subsection{References}

[1] Department for Business, Energy and Industrial Strategy, Energy Consumption in the UK 2016. https://www.gov.uk/government/statistics/energy-consumption-in-the-uk, 2016 (accessed 20 March 2020).

[2] M. Wetherill, W. Swan, C. Abbott, The influence of UK energy policy on low carbon retrofit in UK housing, Retrofit 2012, The University of Salford, Manchester, United Kingdom, 24-26 January, 2012.

[3] Department of Energy \& Climate Change, Smart metering implementation programme DECC's policy conclusions: Early learning project and small-scale behaviour trials.

https://assets.publishing.service.gov.uk/government/uploads/system/uploads/attachment_dat a/file/407539/1_Early_Learning_Project and_Behaviour_Change_Trials_Policy_Conclusio ns_FINAL.pdf, 2015 (accessed 20 March 2020).

[4] M. Weiss, A. Helfenstein, F. Mattern, T. Staake, Leveraging smart meter data to recognize home appliances, 2012 IEEE International Conference on Pervasive Computing and Communications, IEEE, Lugano, Switzerland, 2012, 190-197, https://doi.org/10.1109/PerCom.2012.6199866.

[5] L. Stankovic, V. Stankovic, J. Liao, C. Wilson, Measuring the energy intensity of domestic activities from smart meter data, Appl. Energy 183 (2016) 1565-1580. https://doi.org/10.1016/j.apenergy.2016.09.087.

[6] Fortune Business Insights, Smart Home Market to Reach \$622.59 Billion by 2026. http://www.globenewswire.com/news-release/2020/01/07/1967359/0/en/Smart-HomeMarket-to-Reach-622-59-Billion-by-2026-Increasing-Merger-Acquisition-Activities-toPropel-Growth-Fortune-Business-Insights.html, 2020 (accessed 20 March 2020).

[7] ZDNet, With Amazon, Apple and Google onboard, this new alliance aims to make your smart home work properly. https://www.zdnet.com/article/with-amazon-apple-and-googleonboard-this-new-alliance-aims-to-make-your-smart-home-work-properly/, 2020 (accessed 20 March 2020).

[8] S. Darby, The effectiveness of feedback on energy consumption. A Review for DEFRA of the Literature on Metering, Billing and Direct Displays, Environmental Change Institute, University of Oxford, Oxford, UK, 2006.

[9] K. Buchanan, R. Russo, B. Anderson, The question of energy reduction: The problem(s) with feedback, Energy Policy 77 (2015) 89-96. https://doi.org/10.1016/j.enpol.2014.12.008. 
[10] T. Hargreaves, Beyond energy feedback, Build. Res. \& Inf. 46 (3) (2018) 332-342. https://doi.org/10.1080/09613218.2017.1356140.

[11] Y. Strengers, S. Pink, L. Nicholls, Smart energy futures and social practice imaginaries: Forecasting scenarios for pet care in Australian homes, Energy Res. Soc. Sci. 48 (2019) 108-115. https://doi.org/10.1016/j.erss.2018.09.015.

[12] B. K. Sovacool, What are we doing here? Analyzing fifteen years of energy scholarship and proposing a social science research agenda, Energy Res. Soc. Sci. 1 (2014) 1-29. https://doi.org/10.1016/j.erss.2014.02.003.

[13] P. C. Stern, Individual and household interactions with energy systems: Toward integrated understanding, Energy Res. Soc. Sci. 1 (2014) 41-48. https://doi.org/10.1016/j.erss.2014.03.003.

[14] S. Renström, Supporting diverse roles for people in smart energy systems, Energy Res. Soc. Sci. 53 (2019) 98-109. https://doi.org/10.1016/j.erss.2019.02.018.

[15] E.B.N. Sanders, P.J. Stappers, Co-creation and the new landscapes of design, CoDesign 4 (1) (2008) 5-18. https://doi.org/10.1080/15710880701875068.

[16] F. Sleeswijk Visser, P.J. Stappers, R. van der Lugt, E.B.N. Sanders, Contextmapping: experiences from practice, CoDesign 1 (2) (2005) 119-149. https://doi.org/10.1080/15710880500135987.

[17] J. Trischler, S.J. Pervan, S.J. Kelly, D.R. Scott, The value of codesign: The effect of customer involvement in service design teams, J. Serv. Res. 21(1) (2018) 75-100. https://doi.org/10.1177/1094670517714060.

[18] G. Dove, S. Jones, Using data to stimulate creative thinking in the design of new products and services, Proceedings of the 2014 conference on Designing interactive systems, Vancouver, Canada. ACM, New York, New York, USA, (2014) 443-452. https://doi.org/10.1145/2598510.2598564.

[19] G. Dove, S. Jones, Using Information Visualization to Support Creativity in Service Design Workshops, ServDes, April, 2014, Lancaster, UK. https://openaccess.city.ac.uk/id/eprint/3864.

[20] M. de Wilde, G. Spaargaren, Designing trust: how strategic intermediaries choreograph homeowners' low-carbon retrofit experience, Build. Res. Inf. 47 (4) (2019) 362-374. https://doi.org/10.1080/09613218.2018.1443256. 
[21] T. Kane, S. K. Firth, T. M. Hassan, V. Dimitriou, Heating Behaviour in English Homes: An Assessment of Indirect Calculation Methods, Energy and Buildings, 148 (2017) 89-105. https://doi.org/10.1016/j.enbuild.2017.04.059.

[22] S.A. Cockbill, A. May, V. Mitchell, The assessment of meaningful outcomes from co-design: a case study from the energy sector, She Ji: The J. Des. Econ. Innovation, 5 (3) (2019) 188208. https://doi.org/10.1016/j.sheji.2019.07.004.

[23] C. Lim, K.H. Kim, M.J. Kim, J.Y. Heo, K.J. Kim, P.P. Maglio, From data to value: A ninefactor framework for data-based value creation in information-intensive services, International J. Info. Management 39 (2018) 121-135. https://doi.org/10.1016/j.ijinfomgt.2017.12.007.

[24] T. Tang, T. Bhamra, Changing energy consumption behaviour through sustainable product design. DS 48: Proceedings DESIGN 2008, the 10th International Design Conference, Dubrovnik, Croatia, (2008).

[25] G.L. Shostack, How to design a service, European J. Marketing, 16 (1) (1982) 49-63. https://doi.org/10.1108/EUM0000000004799.

[26] E.B.N. Sanders, E. Brandt, T. Binder, A framework for organizing the tools and techniques of participatory design. PDC'10: Proceedings of the 11th biennial participatory design conference, Sydney, Australia. ACM, New York, New York, USA, (2010) 195-198. https://doi.org/10.1145/1900441.1900476.

[27] M. Foverskov, K. Dam, The Evocative Sketch, in: J. Halse, E. Brandt, B. Clark, T. Binder (Eds.), Rehearsing the future, The Danish Design School Press, 2010, pp. 44-49.

[28] L.G. Tudor, M.J. Muller, T. Dayton, R.W. Root, A participatory design technique for highlevel task analysis, critique, and redesign: The CARD method. Proceedings of the Human Factors and Ergonomics Society 37th Annual Meeting, Sheraton Seattle Hotel \& Towers/Washington State Convention Center, SAGE Publications, (1993) 295-299. https://doi.org/10.1177/154193129303700409.

[29] S. Clatworthy, Service innovation through touch-points: the AT-ONE touch-point cards, Proceedings ServDes 2010, Exchanging Knowledge, Linköping, Sweden, Linköping University Electronic Press, (2012) 25-38.

[30] M. Maguire, Methods to support human-centred design, International J. Human-Computer Stud. 55 (4) (2001) 587-634. https://doi.org/10.1006/ijhc.2001.0503.

[31] M. Stickdorn, J. Schneider, K. Andrews, A. Lawrence, This is service design thinking: Basics, tools, cases, Wiley, Hoboken, New Jersey, 2011. 
[32] D. McCandless, Information is beautiful, Collins, London, 2012.

[33] F.S. Visser, V. Visser, Re-using users: co-create and co-evaluate, Personal \& Ubiquitous Computing 10 (2-3) (2006) 148-152. https://doi.org/10.1007/s00779-005-0023-X.

[34] E.B.N. Sanders, P.J. Stappers, Convivial toolbox: Generative research for the front end of design, BIS Publishers, Amsterdam, the Netherlands, 2012.

[35] H. Pettifor, C. Wilson, G. Chryssochoidis, The appeal of the green deal: Empirical evidence for the influence of energy efficiency policy on renovating homeowners, Energy Policy 79 (2015) 161-176. https://doi.org/10.1016/j.enpol.2015.01.015.

[36] P. Cosar-Jorda, R. A. Buswell, V. Mitchell, Quantifying energy demand reduction considering householder willingness to apply measures, Build. Res. Inf. 47 (7) (2019) 850-864, https://doi.org/10.1080/09613218.2019.1630245.

[37] Energy Systems Catapult, SSH2 Introduction to Heat as a Service.

https://es.catapult.org.uk/reports/ssh2-introduction-to-heat-as-a-service/, 2019 (accessed 20 March 2020).

[38] F. Kensing, J. Blomberg, Participatory design: Issues and concerns. Computer Supported Coop. Work (CSCW) 7 (3-4) (1998), 167-185. https://doi.org/10.1023/A:1008689307411.

[39] M. Stickdorn, M.E. Hormess, A. Lawrence, J. Schneider, This is service design doing: Applying service design thinking in the real world, O'Reilly Media Inc., CA, USA, 2018.

[40] A. Polaine, L. Løvlie, B. Reason, Service design. From Implementation to Practice, Rosenfeld Media, New York, USA, 2013.

\subsection{Appendices (as appropriate)}

